\title{
Labour Force Survey unemployment and benefits durations
}

\section{SUMMARY}

This analytical article uses the Labour Force Survey (LFS) to examine headline patterns of unemployment duration to introduce a comparison of unemployment benefit claim duration from both the LFS and the Jobcentre Plus Administrative system. The article shows the similarities between the two sources in terms of the direction of movement, but also the discrepancies in terms of levels of claimants. The LFS Household dataset is used to look at numbers of claimants within a household and their economic statuses. Finally, the article presents gross flows onto and from unemployment benefits using the Longitudinal LFS.

\section{Background}

he first part of this article considers how headline unemployment

levels have changed in the 200809 recession. This is then followed by considering the extent to which unemployed people remain connected to the labour market by looking at unemployment durations. This brief analysis leads on to a comparison of the differences between the official measure of unemployment as recorded by the Labour Force Survey (LFS) (see Technical note 1) and the numbers of claimants of Jobseeker's Allowance (JSA), a key policy tool used to address labour market attachment. The next section uses the two sources to examine claimants of unemployment benefits by the length of claim (duration), and according to age, education, marital and housing status. The Household LFS dataset (see Technical note 1) is used to add to the individual level analysis by providing an insight into the numbers of claimants in a household. The Longitudinal LFS dataset (see Technical note 1) is used to provide analysis of changes in economic status, for people who began to, or stopped claiming unemployment benefits in a particular quarter.

In Q2 2008 the UK economy recorded a contraction of 0.1 per cent in Gross Domestic Product (GDP). The third quarter of 2009 was the sixth consecutive quarterly fall, meaning that UK GDP was 6.2 percentage points below its Q1 2008 level. The unemployment rate increased for five consecutive quarters from Q2 2008. The weakened positions of the UK goods and labour markets in 2008-09 had important implications for both the finances of individuals and society. This article presents analysis on the number of individuals by unemployment status and whether they claim unemployment related benefits.

Unemployment measures all people who meet the internationally agreed definition of unemployment (set by the International Labour Organisation). It is different from the claimant count, which measures only those people who are claiming unemployment related benefits (Jobseeker's Allowance). While many people will be recorded as unemployed on both measures, not everyone who is unemployed (under the ILO definition) is

\section{Box 1}

\section{LFS re-weighting}

The Labour Force Survey is re-weighted periodically to reflect changes in the UK population. In February 2010 data sets from Q3 2006 to Q4 2009 were re-weighted to reflect ONS's 2009 population estimates and the analysis for these periods reflects this update. However, data from periods prior to this have not been re-weighted. Throughout this article estimates produced from the LFS for periods up to Q2 2006 are weighted to 2007 population estimates. 
eligible for, or chooses to claim Jobseeker's Allowance (JSA). Some unemployed people (especially women) are not eligible for JSA because they have a partner who is in work and/or because of their financial position, which helps increase unemployment, but not the claimant count. Alternatively, while most recipients of JSA would be classified as unemployed, some fall into the 'employed' or 'economically inactive' categories. This means that under some conditions it is possible for the claimant count to be higher than unemployment. ONS has published an explanation of the differences between the LFS unemployment statistics and JSA claimant count statistics in Annex 3 of the Labour Market Overview.

Two factors are fundamental to the relationship between the measures: the fact that economic activity in the LFS is based on self-classification; and the policy context, in terms of eligibility and the success of helping people who claim to actively seek work. This article concentrates on what the LFS does offer in terms of analysis. However, the LFS cannot sufficiently provide accurate estimates of the numbers of people claiming unemployment related benefits to definitively conclude that LFS analysis does not contain some bias. The reasons for this are explained later in this article.

\section{Unemployment before and during the 2008-09 recession}

In Q4 2009 the unemployment rate was

7.8 per cent, an increase of 2.5 percentage points since the contraction in UK output started in Q2 2008. However, in previous periods when GDP has fallen in consecutive quarters, the unemployment rate continued to rise following the return to positive growth. In Q4 2009, the unemployment rate was still 4.2 percentage points below the peak reached in the 1980s (11.9 per cent in Q2 1984) and 2.8 percentage points below the peak reached in the 1990s (10.6 per cent in Q1 1993). On the 30 March 2010, ONS published its estimate of GDP for Q4 2009, this showed growth of 0.4 per cent.

In Q4 1992 the unemployment rate was 10.4 per cent. This fell to around five per cent by the first few quarters of 2000 and remained around this rate until Q3 2008. Disaggregating by sex; the male unemployment rate was consistently higher than the female unemployment rate. The differences between male and female rates have narrowed over time. In Q4 1992 the male unemployment rate was 4.6 percentage points above female unemployment. By
Q1 2004 the series had converged so that the male unemployment rate was within one percentage point of the female rate. This continued until 2009, when increases in unemployment that accompanied the onset of recession in Q2 2008 led the series to diverge. The female unemployment rate rose less than the male, increasing by only 1.8 percentage points between Q2 2008 and Q4 2009 compared to an increase in the male unemployment rate of 3.1 percentage points. In Q4 2009 the male unemployment rate was 2.3 percentage points greater than the female rate.

\section{Claimant count before and during the 2008-09 recession}

From 1992 to 2008 the claimant count rate (the number of people claiming as a proportion of workforce jobs and claimant count levels) followed a downward trend, falling from 9.9 per cent in December 1992 to a low of 2.4 per cent in March 2008. When analysed by sex, a similar pattern to the unemployment estimates is observed: the male claimant count rate is consistently higher than the female rate, and the disparity between men and women narrowed between March 1992 and March 2008 from a 7.3 percentage point difference to 1.9 percentage points. However, the difference had grown to 3.8 percentage points by December 2009. These changes in the claimant count were accompanied by falling unemployment for the period.

The changes in the gap between the two sexes took place while both male and female claimant count rates increased. The male rate rose from 3.3 per cent in January 2008 to a peak of 6.8 per cent in October 2009, while the female rate increased by less; from 1.4 per cent to 2.9 per cent over the same period. The number of claimants increased from 799,300 in January 2008 to a peak of 1,632,500 in October 2009 - the highest level witnessed since April 1997. Following this it fell slightly to $1,612,100$ by December 2009.

\section{Attachment to the Labour Market}

A broad definition of labour market attachment is provided by the International Labour Organisation (ILO) definition of economic activity: if a person is employed, unemployed (looking for work and available), or inactive (but would like to work), they retain varying degrees of attachment to the jobs market. For those people who are unemployed or inactive, the length of time they spend in these states will influence the strength of attachment to the labour market. In this section the LFS is used to examine the duration of unemployment.

The first estimate presented in Figure 1 coincided with the beginning of a sustained recovery in terms of economic output. So, it is interesting to compare the different paths of the short-term unemployed levels (less than 3 months) with the longer term unemployed in the context of the economic recovery following the 1990-91 recession.

Figure 1 shows a time series of unemployment levels by duration beginning in Q4 1992 and ending in Q4 2009. The 'less than 3 months' series shows considerable seasonality, with peaks occurring in Q3 of each year. From 1992 until the end of 2007 there were only short periods where this series was not between 600,000 and 800,000 . This category shows that frictional unemployment, which occurs as a result of the turnover of jobs and job search, is always present in the labour market. Within each of the duration categories there will also be elements of structural unemployment, which is caused by a mismatch in the demand and supply of skills. The last six quarters showed a departure from this pattern with the "less than 3 months' series increasing sharply in Q3 2008, and reaching a high of 915,000 in Q3 2009. In Q4 2009 the level fell to 772,000 . This fall follows the seasonal pattern previously shown by the data, but is not of the same magnitude. This step change is a result of 'cyclical' or 'demand' deficient unemployment; terms which describe changes in unemployment caused by falls in demand for labour which tend to occur during weak economic growth and recessions.

Between 1992 and 2001, the numbers of people unemployed for longer than three months fell. The reduction in numbers of people who were unemployed for 'between 1 and 2 years' between 1992 and 2000 moved this group below the ' 3 to 6 ' and ' 6 to 12 ' month groups. Similarly, over the same period the ' 6 to 12 ' month category changed position in relation to the ' 3 to 6 month category. These changes suggest that longer-term unemployment was eroded between 1992 and 2000, before settling at lower levels for the period 2001 to 2007 .

The numbers of people with longerterm unemployment durations, over six months, increased following Q3 2008. This fits with the small increase in the unemployment rate at the end of 2007 , because a proportion of those who entered 


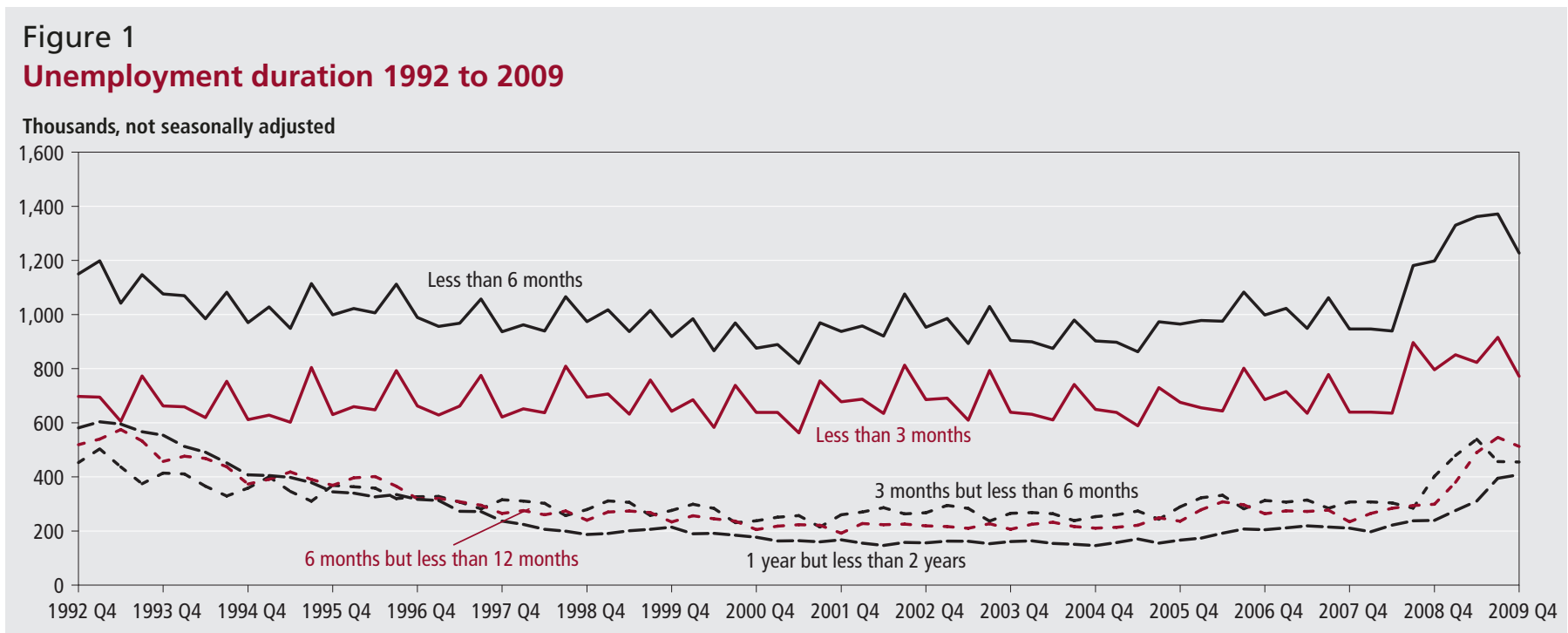

Notes:

Source: Labour Force Survey

1 The 'less than 6 months' series is a sum total of the 'less than 3 months' and the 3 to 6 months groups.

2 Durations of 2 years and over omitted.

3 Estimates for periods prior to Q3 2006 are weighted to 2007 population estimates. Estimates for periods from Q3 2006 onwards are weighted to 2009 population estimates.

unemployment during this period will have remained unemployed, and fed through to cause the first increases in numbers of people in the longer duration groups during 2008. This growth in levels appeared to have slowed in the last two quarters of 2009 for the ' 3 to 6 ' and ' 6 to 12 ' month duration series, but the ' 1 to 2 year' category recorded an increase in Q4 2009.

Some people remain unemployed beyond the two year duration, although this group is not shown in Figure 1. Following a sustained return to GDP growth in Q3 1992, the estimates for people unemployed for two to three years peaked at 305,000 in Q4 1993, while the estimates of people unemployed for more than three years peaked at 425,000 in Q1 1995. The lag in the peak of the 'more than 3 years' group shows how the initial inflow to unemployment of short durations 'ripples' through to longer durations. In this instance, it shows that people continued to declare themselves 'unemployed' and therefore looking for work for some time following the return to positive growth.

As described by Shumway (1993) there are two main approaches to analysing labour market behaviour: human capital models and job search models. These approaches are also relevant in relation to unemployment duration. The human capital models were first developed by Becker (1974), and assume that individual characteristics, such as education and past experience determine the wages and employability of a person. Job search models involve the intensity of job offers in relation to the reservation (read acceptable) wage of an individual and were formulated by Stigler (1961) and Lippman and McCall (1976).

A person's duration of unemployment will be influenced by factors beyond their control, like the economy, and also by individual characteristics which may or may not be within their control. The obvious example, consistent with human capital models is the undertaking of training or education to increase the chances of being hired by an employer. However, Shumway (1993) and Long (2009) have shown that other factors like marital status and whether a person owns or rents their home can also help explain the chances of leaving unemployment. Interestingly, Shumway's work also supports the theory that unemployment benefits increase the risk of remaining unemployed, and therefore lengthening unemployment duration. This is because unemployment benefits may cause job seekers to raise their reservation wage, rather than provide a boost to job search activity. The alternative school of thought supported by Wadsworth (1990) is that the conditionality of unemployment benefits provides a link to the labour market, and encourages job searches, thereby preventing people moving into inactivity.

\section{Comparison of JSA claimant count to LFS unemployment related benefits}

The LFS asks questions regarding the types of state benefits claimed. However, the LFS is not the official source for estimates of unemployment benefits. This is provided by the JobCentre Plus administrative system, which provides the official statistics on
JSA claims, and is known as the claimant count. However, the different LFS datasets allow an examination of unemployment benefit claimant status trends, and most importantly permit analysis of claimants according to individual and household characteristics.

Before examining the LFS results a number of caveats need to be established. The LFS estimates of both types of JSA (contributory and income based) are lower than the official statistics. The difference is larger between LFS estimates of income based JSA and the administrative figures for income based JSA. While contributory JSA estimates in the LFS are closer to the results from the administrative data, the quarterly movements of the two sources are not always consistent. Part of the difference between the two sources is because of nonresponse to the benefits questions in the LFS. In Q4 2009, of the people who stated they were claiming benefits, around 400,000 (35 per cent) answered 'don't know' when questioned about their JSA claim type. This is twinned with survey weaknesses around proxy responses and uncertainty over the exact type of benefits claimed. ONS has analysed the differences between the administrative data source and the LFS in the past and further detail can be found in Jenkins and Laux (1999) and Barham, Laux and Roberts (2003).

Figure 2 shows the levels of JSA claimants plotted with the levels of unemployment benefit claimants recorded by the LFS (using the variable CLAIMS which was introduced in Spring 1998). The JSA claimant count measure is consistently greater than the number of claimants 


\section{Figure 2}

Figure 2: JSA claimant count ${ }^{1}$ and LFS claimants, ${ }^{2}$ Q4 1998 to Q4 2009

Thousands, all economic statuses, not seasonally adjusted

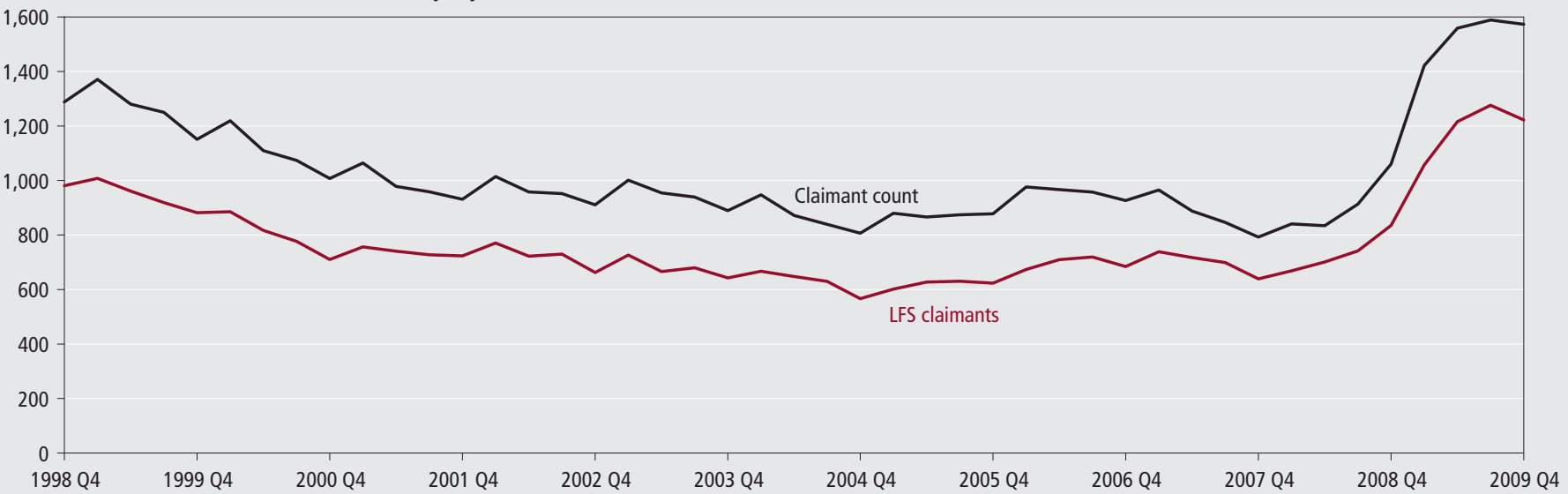

Notes:

Source: Jobcentre Plus administrative system; Labour Force Survey

1 Claimant count series presented is a quarterly three month average.

2 LFS estimates for periods prior to Q3 2006 are weighted to 2007 population estimates. Estimates for periods from Q3 2006 onwards are weighted to 2009 population estimates.

\section{Figure 3}

\section{Unemployment benefit duration, comparison of sources, ${ }^{1}$ Q4 1998 to Q4 2009}

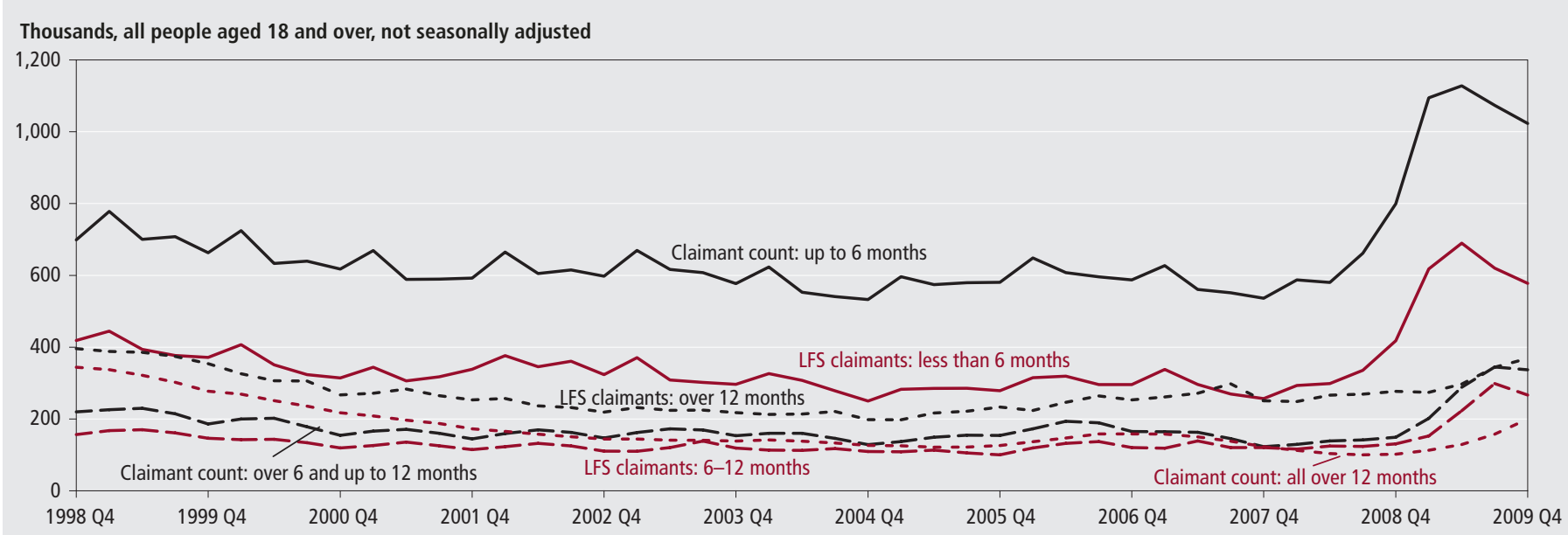

Note:

Source: Jobcentre Plus administrative system; Labour Force Survey

1 LFS estimates for periods prior to Q3 2006 are weighted to 2007 population estimates. Estimates for periods from Q3 2006 onwards are weighted to 2009 population estimates.

Figure 4

LFS ${ }^{1}$ claimants and JSA claimants aged 25-49: by duration

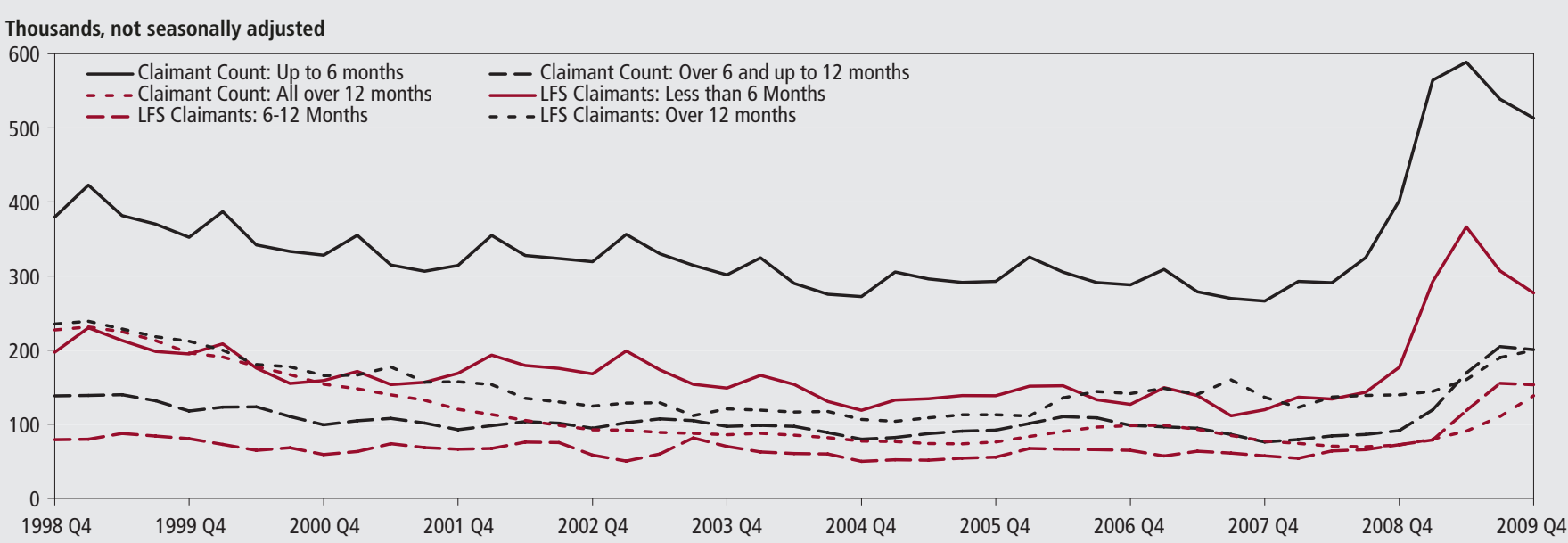

Note:

Source: Jobcentre Plus administrative system; Labour Force Survey

1 LFS estimates for periods prior to Q3 2006 are weighted to 2007 population estimates. Estimates for periods from Q3 2006 onwards are weighted to 2009 population estimates. 
identified in the LFS. However, during 2008 the two series converged. The gap narrowed from a difference of 307,000 in Q4 1998 to 133,000 in Q2 2008. Since Q2 2008 this trend has reversed, widening to 351,000 in Q4 2009. Some of this difference is attributable to uncertainty over the type of benefits claimed by LFS respondents.

\section{Claimant duration in the LFS and administrative data (JSA)}

The LFS asks the length of time that a person has been claiming benefits. This can be used to generate an estimate of the number of people claiming unemployment benefits for the same duration categories used in the claimant count.

Figure 2 showed that between Q4 1998 and Q4 2004 there was a downward trend in the year on year changes in the number of claimants according to the LFS. Figure 3 shows that of the LFS estimates, the less than 6 months' category has shown the largest increase on the year to Q2 2009. These changes are consistent with the official claimant figures produced by the Jobcentre Plus administrative system and the operation of the labour market as people become ineligible or stop claiming (for example, because they find work of more than 16 hours a week).

Figure 3 also provides a comparison of benefit claimant duration for three duration groups taken from the LFS and the Jobcentre Plus administrative system. The LFS estimates are for all people aged 18 and over, regardless of their economic status. It can be seen that the LFS underestimates the number of unemployment related benefit claimants in the group 'less than 6 months' compared to the JSA claimant count. This is emphasised by the fact that since 2003 the total claimant estimates from the LFS (see Figure 2) are of a similar magnitude to the official 'less than 6 months' levels taken from the Jobcentre Plus administrative system. Having said this, both 'less than 6 month' series follow a similar path over the period presented, with similar peaks and troughs. Figure 3 also shows that the LFS underestimate for the "between 6 and 12 months' group is not as large as the underestimates for shorter claimant durations. Where the estimates are of a similar order of magnitude, assuming that neither the JSA system nor the LFS has a particular bias in terms of the people who claim or declare that they claim, the LFS may be able to provide further analysis of the characteristics of the groups with longer claimant durations.

The LFS estimate of the number of claimants with durations of over 12 months is higher than that of the official claimant count. This difference is likely to be caused by factors relating to the methods used to produce estimates from the two sources.

The claimant count official statistics are a snapshot of JSA on a particular day. If people are late in informing the Jobcentre they wish to continue to claim unemployment benefits they are recorded as an outflow from the claimant count. Therefore, when they inform the Jobcentre they wish to continue to claim JSA, their duration of claim appears shorter than is really the case.

When people respond to the LFS they may not accurately report the type of benefit they receive. For example, an individual who claims JSA and then moves to a New Deal benefit may still state that they are claiming unemployment benefits. However, some New Deal arrangements do not count as unemployment benefits. Furthermore, people may not always accurately report their unemployment durations in both sources, because they do not include short durations of unemployment. Or alternatively, people may misreport their duration because they think of their time out of work, rather than their time unemployed (when they must be looking and available for work). There is also a time constraint attached to some unemployment benefits, particularly for people with an unbroken claim period. So it is possible that some of the people claiming for longer durations are actually receiving another type of benefit.

\section{Unemployment benefit claims: by age}

The first individual characteristic considered for analysis is age. Here the 18-24 and 25-49 age groups are given most consideration; this is because people in these groups are most likely to be eligible for unemployment benefits. Younger people, aged 16 and 17 are only eligible if they meet specific criteria, meanwhile those in the 'over 50' age group who are above the state pension age will normally be in receipt of pension credits rather than unemployment related benefit.

Figure 4 compares people aged 25-49 who are identified in the LFS as claiming unemployment related benefits (LFS claimants), with people of the same age group from the Jobcentre Plus computerised administrative system (the Claimant Count). The LFS Claimants and JSA Claimant Count move in similar directions over time for each duration group during the period shown. When single month estimates from the claimant count are used, rather than three month averages (as shown in Figure 4) the similar seasonal patterns are more noticeable.

Both the LFS and JSA claimant levels, for the 'less than 6 months' groups, were lower in Q4 2007 than in Q4 1998 (falling by 78,000 and 113,000 respectively). Having said this, the difference in the two measures for the 'less than six months' category, ranged from 136,000 to 193,000 between Q4 1998 and Q4 2007. Sharp increases in both series following Q2 2008 (both peaked in Q2 2009) widened the gap to 236,000 by Q4 2009.

The number of claimants in the ' 6 to 12 months' groups for both sources were relatively stable over the period presented, and lower than in the 'less than 6 months' groups. However, the relationship between the ' 6 to 12 months' and 'over 12 months' groups was different, depending on the source. In the LFS, the 'over 12 months' unemployment benefit group was higher than the ' 6 to 12 month' group. However, the relationship between the two longer duration groups in the JSA system was not as straightforward. Before 2003, the 'Claimant Count: Over 12 months' was higher than the 'Claimant Count: 6-12 months group'. Post 2003, the 'over 12 months' group levels were below the ' 6 to 12 months' group levels, meaning that there were fewer long-term claimants in relation to shorter durations in this age group (a success from a policy perspective). However, different conclusions might be drawn in relation to the success of preventing long-term benefit dependence if the LFS is used, which emphasises the importance of understanding the LFS' weaknesses in relation to estimating unemployment benefits.

Analysis of claimants aged 18-24 (not presented) reveals similar patterns to those aged 25-49. Most claimants are in the 'less than 6 months' groups, but the levels of both sources did not change by much between Q4 1998 and Q4 2007. The LFS claimant level fell by 59,000 , while the Claimant Count fell by 20,000. Following the onset of recession in Q2 2008, both series increased sharply and the difference between the two increased to 169,000 in Q4 2009 (the difference between the two sources had been between 66,000 and 116,000 for the past ten years). In Q4 2009, the LFS recorded 204,000 claimants who were aged 18-24 and had been claiming less than 6 months, while the Claimant Count recorded 373,000 . 


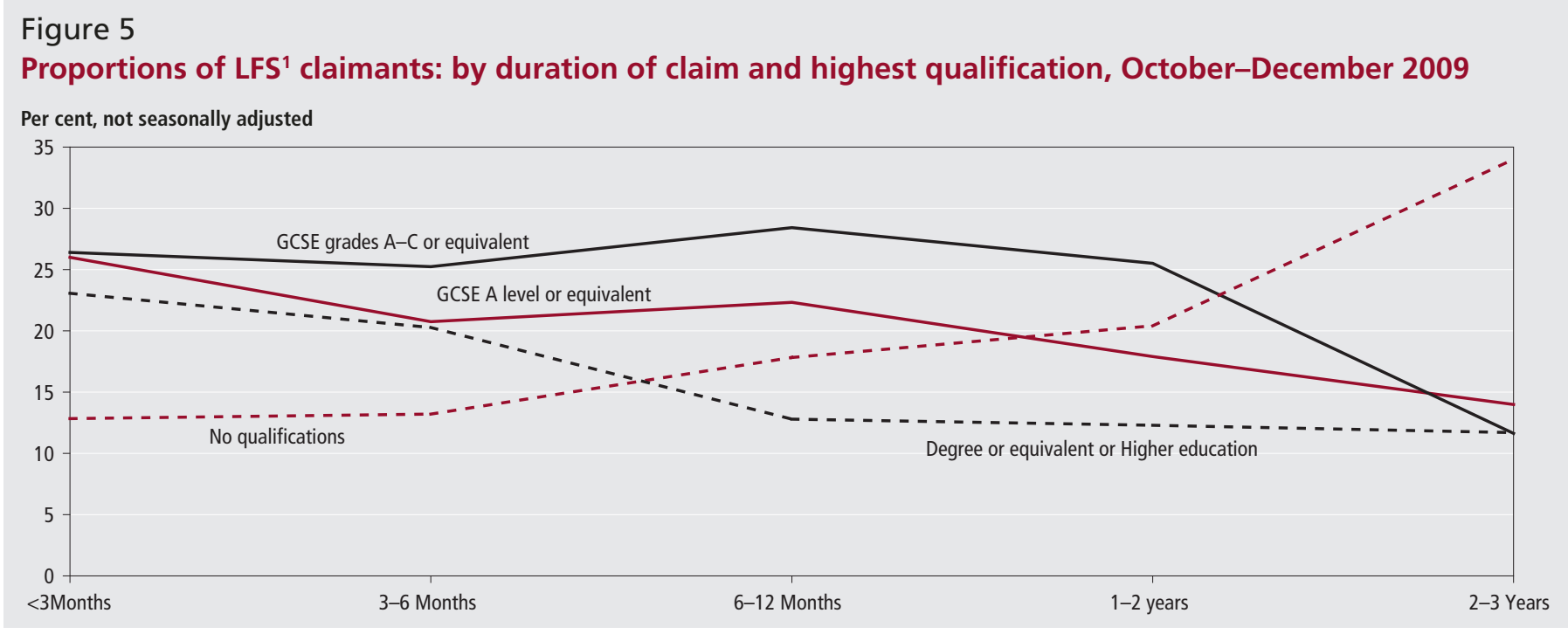

Note:

Source: Labour Force Survey

1 LFS estimates for periods prior to Q3 2006 are weighted to 2007 population estimates. Estimates for periods from Q3 2006 onwards are weighted to 2009 population estimates.

\section{Figure 6}

Proportions of LFS 1 claimants: by duration of claim and housing tenure, October-December 2009

Per cent, not seasonally adjusted

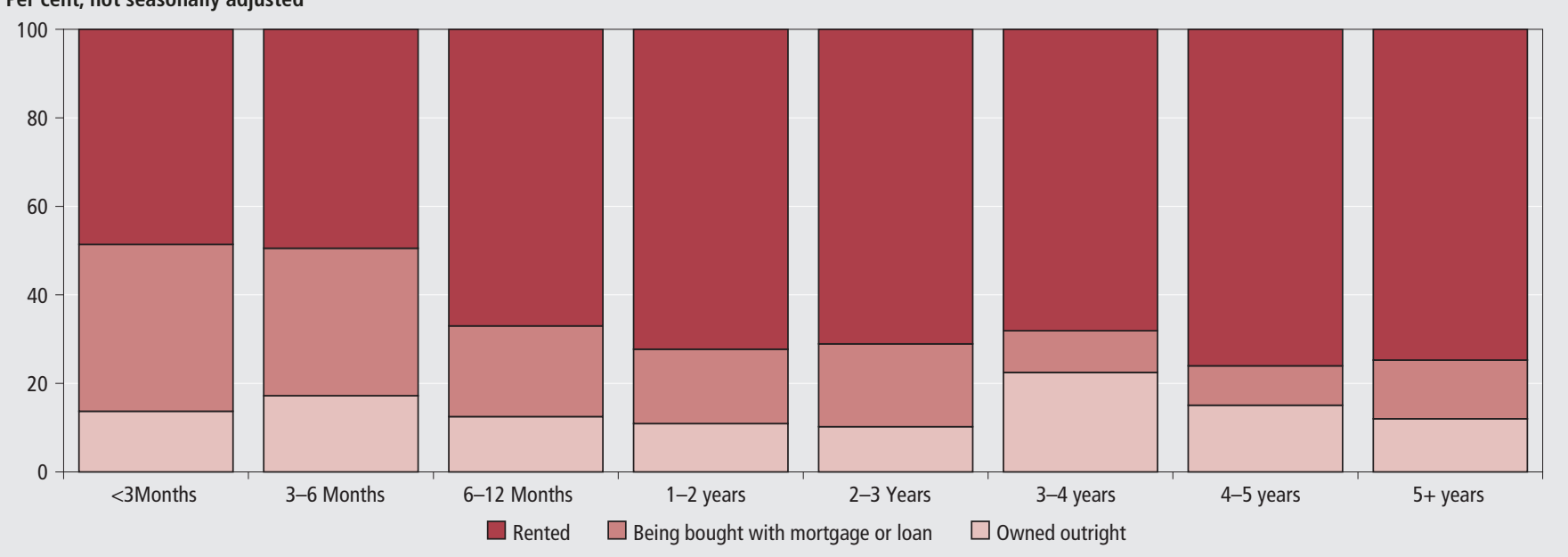

Note:

Source: Labour Force Survey

1 LFS estimates for periods prior to Q3 2006 are weighted to 2007 population estimates. Estimates for periods from Q3 2006 onwards are weighted to 2009 population estimates.

Figure 7

Levels of more than one claimant in a household, Q2 1998 to Q2 2009

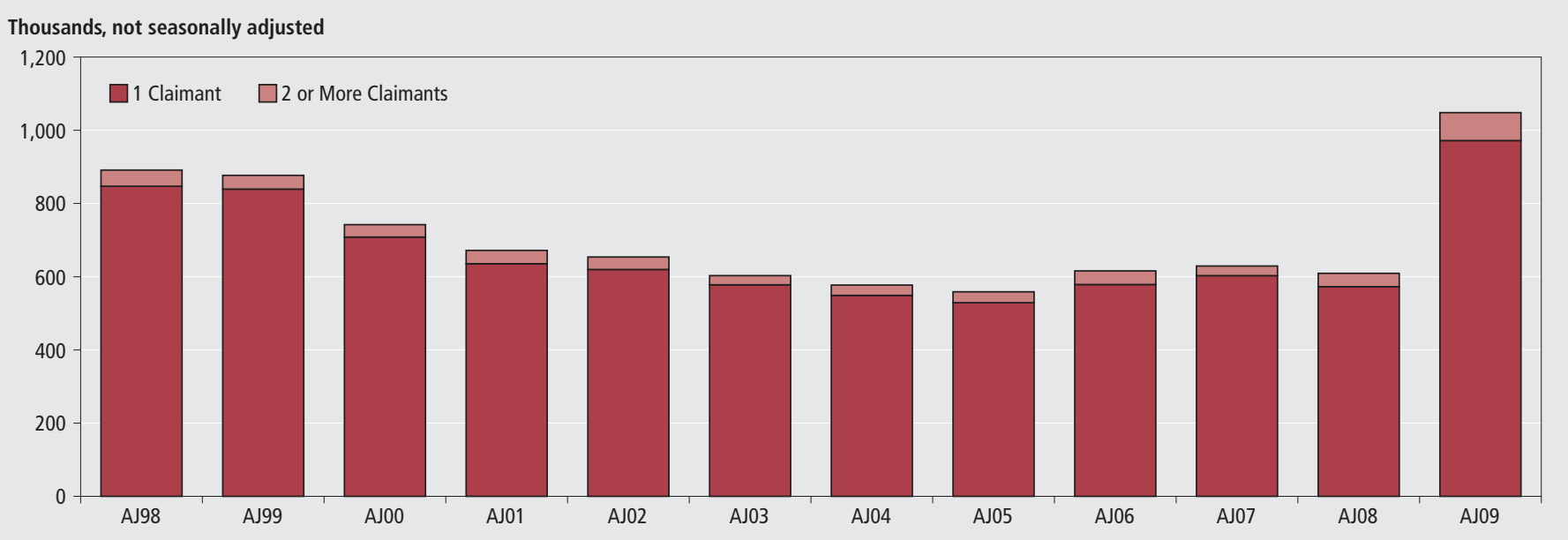

Source: Household Labour Force Survey 
The number of claimants in the ' 6 to 12 months' group for both sources were similar, and relatively stable from Q4 1998 to Q4 2007 at around 30,000-50,000 for the Claimant Count and 30,000-60,000 for the LFS. By contrast, the claimant count for durations over 12 months was different from the equivalent series from the LFS: the claimant count fell from 32,000 in Q4 1998 to stabilise below 12,000; the LFS series did fall from 50,000 in Q4 1998 to fluctuate between 30,000 and 40,000 up until Q3 2005 , after which it increased steadily to 85,000 in Q4 2009.

Relative to younger age groups, longer durations of unemployment benefit claims are more prevalent in both the LFS and Claimant Count for those aged 50 and over. For durations of over 12 months, the LFS estimates were higher than the Claimant Count figures in most periods. The largest difference, 59,000 occurred in Q4 2009. Both sources recorded similar levels of claimants for benefit claim durations of six to twelve months between Q4 1998 and Q4 2009, with the Claimant Count generally being greater over the period.

Overall, both sources were consistent in terms of their direction of movement and showed increases in longer durations as the 2008-09 recession unfolded. The two sources also confirm that durations of benefit claims appear to vary according to age. For younger people shorter durations might be expected because of more flexible job search patterns, as well as opportunities to undertake training and government policies targeted at them. At the other end of the age distribution, unemployment benefit claim duration for those aged 50 and over appears to be concentrated in longer claim periods.

\section{LFS benefit claims by individual characteristics}

The added benefit of using the LFS to examine people claiming unemployment benefits is that it provides the opportunity to analyse individual characteristics such as education, marital status and housing tenure. These particular characteristics have been found to be significant when examining unemployment duration (Long, 2009). This section comments on their relationship in relation to unemployment benefit claim status.

\section{Education}

The qualifications held by an individual can be viewed as either: an investment in human capital (see Becker 1974) in order to earn greater financial rewards; or a signal of suitability for employment, with higher qualifications generally being valued more highly by employers. Given this, it is expected that those people claiming unemployment benefits who have higher qualifications are less likely to remain unemployed (and therefore claiming) for longer durations. This is shown in Figure 5 where the proportion of people claiming unemployment benefits who have degree or higher level qualifications falls from 23.1 per cent for durations of up to three months, to a low of 11.7 per cent for claim spells between two and three years.

The proportion of people claiming unemployment benefits who have no qualification is relatively low for shorter durations, but rises sharply to 34.0 per cent for durations between two and three years.

The proportion of people claiming for less than three months (as recorded by the LFS) whose highest qualifications were GCSE grades $A^{*}-C$ was 26.4 per cent in Q4 2009. The impact of the high unemployment benefit numbers in late 2008 for 'less than 3 months' can be seen in Figure 5 for the GCSE grade group, because by Q4 2009 the higher proportions had fed through to the ' 6 to 12 ' months (28.4 per cent) and ' 1 to 2 ' years ( 25.5 per cent) groups. The proportion of claimants with A-Level or equivalent qualifications was lower for longer durations of claims (14.0 per cent for durations of 2 to 3 years), than the less than 3 months group (26.0 per cent).

\section{Housing tenure}

In Long (2009), it was shown that the type of accommodation in which people live can affect the conditional probability of exiting unemployment. This is likely to be controlling for a number of factors that may be unobservable, for example attitudes to work, and employers' perceptions of the areas in which people live. However, the type of housing people occupy will also influence the financial incentives to find new work when they become unemployed. Figure 6 shows that the proportion of people who are in the process of buying their houses through a mortgage and are claiming unemployment benefits decreases as duration increases. By contrast the proportion of people claiming unemployment benefits who live in rented accommodation or own their houses outright increases at longer durations.

\section{Marital Status}

Presenting the numbers of LFS claimants by marital status reveals that the majority of those who claim unemployment related benefits are not 'Married, Cohabiting or in a Civil Partnership'. In Q4 2009 66.0 per cent of claimants were in this category. In Q2 2008, the first quarter of recession, this proportion was 1.9 percentage points higher. The difference between the proportion of claimants who are married and those who are not married will be influenced by the rules of the benefit regime. For example, people who are married, cohabiting or in Civil Partnerships can claim a couples' JSA rate. However, being married, cohabiting or in a Civil Partnership may be related to other characteristics and behaviours that reduce the likelihood of claiming unemployment benefits.

\section{Unemployment benefit claims by household}

The LFS household dataset (see Technical Note 1) can be used to investigate the numbers of claimants in a household. In this section the number of households with one or more claimants is shown.

In Q2 1998 there were just over 890,000 households in the UK with one or more claimants. As can be seen in Figure 7, according to the LFS the numbers of households with two or more claimants were in the minority. For mean tested benefits, the household is often assessed. This means that in the case of incomebased JSA it is possible that only one person is able to claim for the household. Between Q2 1998 and Q2 2005 the number of households with people claiming unemployment related benefits fell in relation to the previous year. In Q2 2005, there were close to 560,000 households with resident claimants. In Q2 2008 there were 609,000 households with claimants. This increased to reach 1.05 million by Q2 2009. This analysis by household reinforces the messages from the analysis of the official claimant count (the JSA claimant count) and the person level LFS estimates.

\section{Economic status of household}

By further analysing the estimates produced in the previous section the relationship between partners in a household, their economic status and unemployment benefit claims can be examined. In Figure $\mathbf{8}$ four different economic mixes are presented: households that contain people who are employed and unemployed; households where all persons are unemployed; households which contain unemployed and inactive people only and households where all persons are inactive. There are other 
Figure 8

One or more claimants in household: by selected economic mix, Q2 1998 to Q2 2009



Figure 9

Levels of unemployment: by claimant status, Q4 1998 to Q4 20091

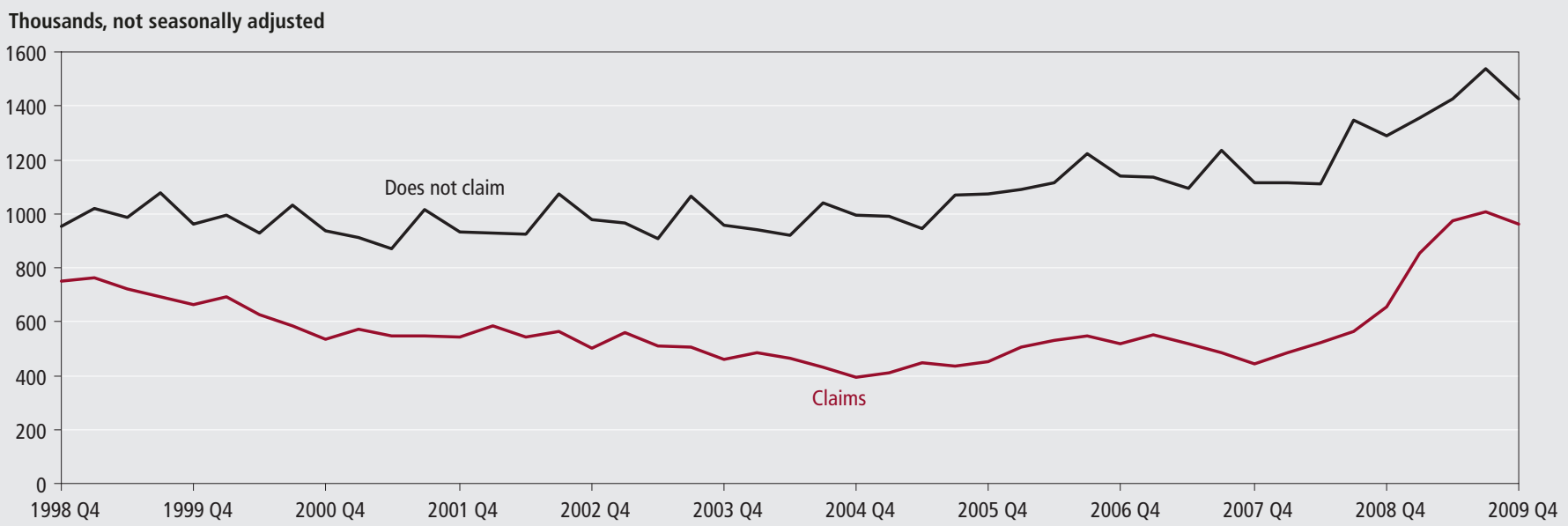

Note:

Source: Labour Force Survey

1 LFS estimates for periods prior to Q3 2006 are weighted to 2007 population estimates. Estimates for periods from Q3 2006 onwards are weighted to 2009 population estimates.

possible permutations of economic statuses which are not shown in Figure 8 because their levels do not contribute as much to the total number of households with one or more claimants.

In each of the quarters presented, the largest group with one or more claimants was those households where all persons were unemployed. The series reached a low for the period between 1998 and 2009 in Q2 2004, when there were 126,000 households with one or more claimants. Following this low, the number of households with one or more claimants, where all persons were unemployed, increased by almost 20,000 in the four years to Q2 2008. However, between Q2 2008 and Q2 2009 the series increased by a further 90,000 .

The two series: households with unemployed and inactive people, and households with employed and unemployed both showed steady declines for most of the period, before increasing in the year to Q2 2009. However, the number of households with one or more claimants where all persons were inactive was relatively constant at around 50,000 households.

\section{Changes in economic and benefit status}

Evidence from the LFS and the Jobcentre Plus administrative system has shown that the numbers of people with longer unemployment durations and longer claims durations have begun to increase in the past year. The longitudinal LFS (see Technical Note 1) provides a further insight into movements from one economic status to another. It does this by recording the economic status of a person in one quarter and then recording their economic status in the following quarter.
It is possible for people to claim unemployment benefit whether they are employed, unemployed or inactive. However, by identifying which economic status people were in allows an insight into pressures on the individual and the State. This is because as employment and other income falls the need to claim unemployment benefit may rise. Furthermore, the eligibility rules for unemployment benefits can provide an incentive to either start looking for work, to look for work more thoroughly, or to consider job offers that would not have been considered earlier in the unemployment spell. From the point of view of the State, an increase in people with only benefits as a source of income means not only an increase in government expenditure, but also the need to consider welfare implications in terms of the distribution of wealth within the economy. 


\section{Claimant levels by economic status}

This section examines the number of people who claimed/did not claim unemployment related benefits between 1998 and 2009 . This was done using the quarterly LFS, meaning the numbers are stock estimates. Estimates are provided for people who are both unemployed and benefit claimants, as identified by the LFS. Estimates for people in other economic statuses are also considered.

In Figure 9 it can be seen that the number of unemployed JSA claimants decreased from 750,000 to around 440,000 between 1998 and 2004. A sustained increase in unemployed people claiming unemployment benefits began in Q4 2007, when it stood at 444,000. By Q3 2009 the level had reached 1 million.

For the period presented, more unemployed people did not claim benefits than those that did. In Q4 1998, 950,000 unemployed people did not claim, and 750,000 people did claim. In Q4 2008 there were 860,000 unemployed people who stated they had claimed, and 1.3 million who stated they did not claim unemployment benefits. However, since the onset of the recession it can be seen that the gap between claiming and not claiming has reduced for unemployed people. In Q4 2009, the gap was 470,000. This is because the 'Does not claim' series increased by 316,000 (to reach 1.5 million in Q3 2009).

Between Q1 2004 and Q3 2008, there were on average 52,000 people who reported claiming unemployment related benefits, and also stated they were in employment. Following Q3 2008 the number of employed claimants increased to 85,000 in Q4 2009. This can be explained by the fact that it is possible to be employed below a 16-hour threshold and still claim JSA. The number of people who were in employment and not claiming benefits steadily increased from 28.3 million to 29.4 million between Q1 2004 and Q3 2008, before falling back to 29 million by Q4 2009. This is influenced by the fall in employment levels that occurred over this period.

The inactivity series was broadly flat for people who stated they claimed unemployment related benefits. Between Q1 2004 and Q1 2009 the series has fluctuated between 121,000 and 186,000. In Q3 2008, there were 128,000 people who said they had claimed unemployment related benefits, but according to ILO definitions were inactive. This had increased to 184,000 in Q3 2009, but decreased to 177,000 in Q4 2009.

Overall, the changes in claimant levels by economic status show that during the 2008-09 recession the majority of the claimant increase came from people that were both ILO unemployed and claiming unemployment benefit. The importance of this finding is that the ILO definition of unemployment indicates a degree of labour market attachment, whereas some reasons for becoming inactive denote detachment from the labour market, for example 'not seeking, long-term sick or disabled'.

However, the rules on eligibility for claiming unemployment benefits mean that inactive people should not be on unemployment benefits. Possible explanations for these estimates include: people are correctly receiving benefits but are confused when reporting in the LFS which benefits they are receiving, or people are receiving unemployment benefits when they should not. Over the period Q1 2004 to Q4 2009 the number of people who were inactive and not claiming unemployment benefits has fluctuated between 10.9 million and 11.4 million.

From stock estimates it is not possible to definitively identify the new economic or claimant statuses causing changes in the levels of inactive claimants. However, the changes in economic status flows can be seen by using the longitudinal datasets in the next section.

\section{Unemployed benefit claims by change in economic status}

This section looks at changes in economic status and benefit claims using the two quarter longitudinal LFS. As stated previously, some flows data is already published on a monthly basis as part of the regular Labour Market Overview. The Labour Market Overview explains that the gross flows data are experimental statistics, and as such should be treated with caution. More comprehensive discussions of the reasons for treating them with caution can be found in Brook and Barham (2006) and Jenkins and Chandler (2010). These articles explain how the datasets are produced whilst adjusting for non-response bias and acknowledging that response error bias exists.

There are nine possible movements relating to changes in economic status. For example, a person can 'flow' from employment to unemployment between two quarters and this would count as one of the movements or flows. Figure 10 shows levels of people by selected changes in economic status and whether they started to claim unemployment benefits. The period presented is between Q1 2003 and Q3 2009 (longitudinal files are not readily available before 2003 and at the time of publication the Q4 2009 file was not available). The figure shows that the largest change in economic status was from employment to unemployment for people who claimed in a particular quarter and were not claiming unemployment benefits in the previous quarter. The increase in this group after Q3 2008 is related to the similar increase seen in Figure 9, which showed the increase in claimant levels as a proportion of unemployment over the same period.

After Q2 2008 the flows into unemployment and people who remained in unemployment contributed the most to inflows onto unemployment benefits. Although other changes in economic status did not contribute to the same extent, and the numbers are relatively small, there are important implications in changes for these groups. For example, increases in the group 'still in employment' would be consistent with an increase in part-time working below 16 hours. This could mean that although people have remained in employment, their gross income has been reduced to the point where they had needed to claim unemployment benefits.

Figure 11 shows people who stopped claiming unemployment benefits and changes in their economic status. As would be expected, the main change in economic status coinciding with an outflow from unemployment benefits is a move from unemployment to employment. Outflows also increased from people who remained in unemployment after Q2 2008. As discussed earlier in this article, some of these people may have stopped claiming because of the length of their claim spell. Another reason for outflows from benefits in the 'still unemployed' group could include a partner finding employment. However, when the inflows for this group, post Q2 2008, are compared with the outflows from Figure 11, it can be seen that the levels of people beginning to claim unemployment benefits were still higher. The outflows from benefits for people remaining in inactivity between two quarters peaked in Q4 2007, one quarter after a peak in the inflows onto unemployment benefits. However, it then reverted back down to around 30,000 after Q2 2008.

The increase in outflows of people 


\section{Figure 10 \\ Changes in economic status for inflows to unemployment benefits}

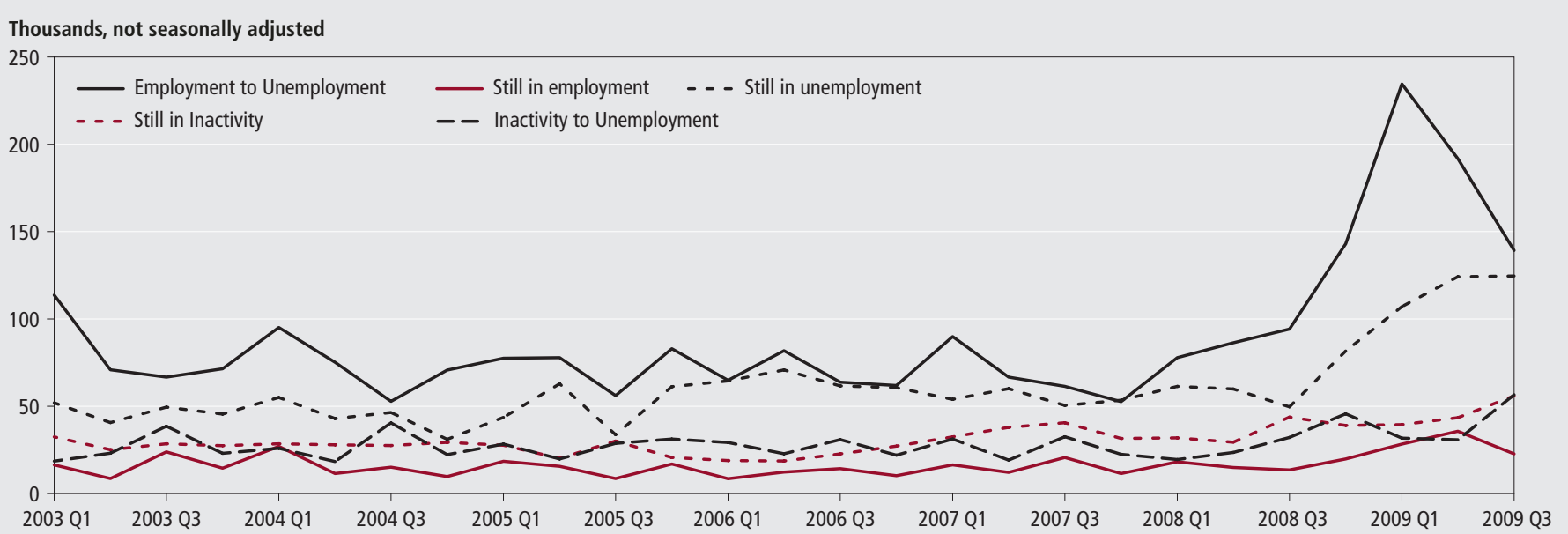

Source: Longitudinal Labour Force Survey (2 quarter)

Figure 11

\section{Changes in economic status for outflows to unemployment benefits}

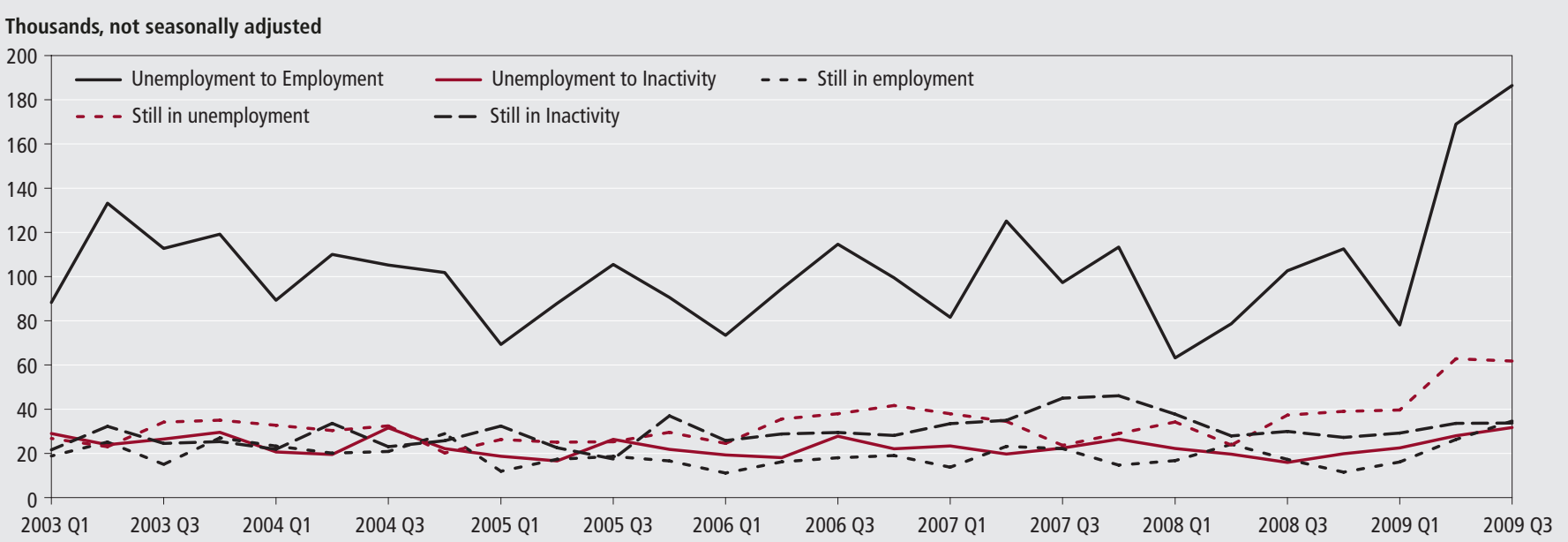

moving from unemployment to

employment shows that even in a recession people are able to find work. So it is worth noting the large increase in Q2 2009 is noticeably greater than any of the increases in the previous six years.

\section{Conclusion}

Differences exist between the two sources (LFS and JSA Claimant Count) because of respondents causing classification errors. These errors impact not only on the headline LFS estimates of unemployment benefit claimants, but also on the estimates of claimants by duration. In order to analyse unemployment as a status the LFS can be used, both for examining characteristics of those unemployed and the duration that they are in that status. However, it is important to recognise the limitations of the LFS. The levels of both unemployment and claimant count are strongly related, as shown by the fact that in Figure 1 short-term unemployment less than 6 months, followed a similar path to the claimant count duration of the same period (see Figure 3). However individual circumstances, for example savings, can determine that someone is unemployed, but does not claim unemployment benefits.

During the 2008-09 recession both unemployment and the claimant count increased. This article has demonstrated that the majority of the increase in the claimant count (as estimated by the LFS) mainly came from people who were unemployed (shown in Figures 9 and 10). This is important because of its implications for labour market attachment. If people declare themselves as unemployed rather than inactive, they are stating they are 'ready and available' to work and have 'actively looked' for work.

As stated in the articles cited and shown again here, the LFS estimates of levels of unemployment benefits are noticeably different from those provided by the
Source: Longitudinal Labour Force Survey (2 quarter)

official JSA system. Furthermore, when analysed by duration, the relationship between the two sources changes (for shorter durations the LFS estimates are lower, and for durations of over 12 months the LFS estimates are higher). Having said this, the two sources do follow similar paths over time.

The LFS has shown it can provide constructive insights into benefit analysis by looking at characteristics that are not necessarily provided in headline statistics from the JSA system. When analysing benefit claims by duration in this article the LFS has shown that: there are a higher proportion of non-married people in the groups who have claimed longer; similarly renting and social housing are more prevalent in the longer benefit duration groups; and finally people with lower human capital (education) contribute more to the levels of the longer benefit durations. This descriptive analysis is consistent 
with both economic theory and empirical evidence.

The LFS also provides the opportunity to look at changes in the number of benefit claimants by household. This analysis showed that between Q2 2008 and Q2 2009 the number of households with 'one or more' claimants increased by 72 per cent. The increase in claimants by household has been driven by all potential workers in the household reporting their economic status as 'unemployed' (meaning they have been made redundant or moved from economic inactivity to economic activity). This emphasises the link between individual and household economic statuses in relation to unemployment benefits.

The origins (in terms of economic status) of new unemployment benefit claimants was analysed using the Longitudinal LFS, and showed that during the 2008-09 recession the sharpest increase of inflows onto unemployment benefit came from people who had moved from employment to unemployment. However, the numbers of people who were 'still in unemployment' also rose steadily. This highlights that although unemployment and claiming unemployment benefits are related, the point at which a person enters one of the two groups may differ. This may be because of eligibility, and/or personal financial circumstances. The analysis of outflows from benefits claims showed that even in a recession people stop claiming because they find employment. In fact, this was the main driver for outflows.

\section{ACKNOWLED GEMENTS}

The authors would like to thank Jessica Coleman for her help in producing this article and Bob Watson and Craig Lindsay for their comments.

\section{CONTACT}

(凶)elmr@ons.gov.uk

\section{REFERENCES}

Barham, C Laux, R and Roberts, S (2003) 'The role of working age benefits in understanding labour supply', Labour Market Trends pp 341-347

Becker, G (1964) 'Human Capital' New York: University of Columbia Press

Brook K and Barham C (2006) 'Labour Market Gross Flows data from the Labour Force Survey' Labour Market Trends Jenkins J and Chandler M (2010) 'Labour Market Gross Flows data from the Labour
Force Survey' Economic \& Labour Market Review

Jenkins, J and Laux, R (1999) 'Evaluation of new benefits data from the LFS', Labour Market Trends 107 (9) pp505-515

Lippman, S and McCall, J (1976) 'The economics of Job Search: A survey' Economic Inquiry 34 pp 155-89

Long, K (2009) 'Unemployment durations: evidence from the British Household Pane

Survey', Economic \& Labour Market Review 3 (10) pp 48-54

Office for National Statistics, Labour Market Overview

www.statistics.gov.uk/downloads/theme labour/LMS_QandA.pdf

Shumway, M (1993) 'Factors influencing unemployment duration with a special emphasis on migration: An investigation using SIPP data and event history methods, The Journal of the RSAI (72) pp 159-176

Stigler, G (1961) 'Information in the labour market', Journal of Political Economy, $69 \mathrm{pp}$ 213-25

Wadsworth, J (1990) 'Unemployment Benefits and Search Effort in the UK Labour Market', Economica (58) pp 17-34 


\section{TECHNICAL NOTE 1}

\section{Labour Force Survey datasets}

\section{Quarterly Labour Force Survey (LFS)}

The Quarterly Labour Force Survey is a key source of information on the labour supply of individuals. The LFS is a quarterly survey of some 53,000 households per quarter. Each household is surveyed over five quarters, with the final (fifth) interview one year after the first. It is designed to provide robust national labour market and macro-economic information, but its sample size is insufficient to provide reliable data at local level.

The data is weighted to allow the sample to provide estimates relating to the total population and to minimise non-response bias. The weights are based on the age and sex structures of the sample and of the population.

Further information on the design of the Quarterly LFS can be found in Volume 1 'Labour Force Survey User Guide: Background and Methodology'.

www.statistics.gov.uk/statbase/Product.asp?vInk=1537

\section{Household and Family LFS Data}

Although the LFS has traditionally been used to provide information on individuals in the labour market, the survey also collects information on the household and family unit. This means data are available for households and families as well as for individuals. The LFS is a unique source of detailed information about the ways that households and families behave in relation to the labour market. As the LFS was designed and developed as a survey focussing on individuals, ONS has decided to produce separate LFS datasets suitable for analyses at household and family level.

This has involved making adjustments to the datasets to correct inconsistencies and discontinuities that in the past affected the recording of household and family structure. Examples of these adjustments include adding new derived variables for use in analysing economic activity at household and family level, and deriving household level weighting factors.

Further information on the Household and Family dataset can be found in Volume 8 'Household and Family Data' of the Labour Force Survey User guide.

www.statistics.gov.uk/statbase/Product.asp?vInk=1537

\section{Longitudinal LFS Data}

Although the Labour Force Survey (LFS) is a cross-sectional survey, a longitudinal dataset can be created over a limited time interval because respondents in the LFS sample are interviewed for five consecutive quarters.

A two-quarter longitudinal dataset is produced at each LFS quarter which combines survey variables for each respondent at two consecutive quarters. Since 20 per cent of the LFS sample is replaced with a new sample at each quarter, the sample size of the two-quarter longitudinal dataset is about 80 per cent of a cross-sectional LFS dataset. The datasets include a flow variable which gives a count of the number of respondents who are employed, unemployed or inactive at both quarters or who experience one of six possible changes of state.

A five-quarter longitudinal dataset is also produced at each LFS quarter which includes survey responses at five consecutive quarters. However, due to the rotation of the LFS sample and attrition over five quarters, the sample size of a five-quarter dataset is less than 20 per cent of a cross-sectional LFS dataset.

Further information on the longitudinal dataset can be found in the 'LFS Two Quarter and Five Quarter Longitudinal dataset User Guide' which is available on the data archive website www.data-archive.ac.uk/doc/6201/mrdoc/pdf/longitudinal.pdf 